\title{
LA IMPORTANCIA DEL CONSTRUCTO: Ética y responsabilidad social en la formación de emprendedores en la Universidad EAN
}

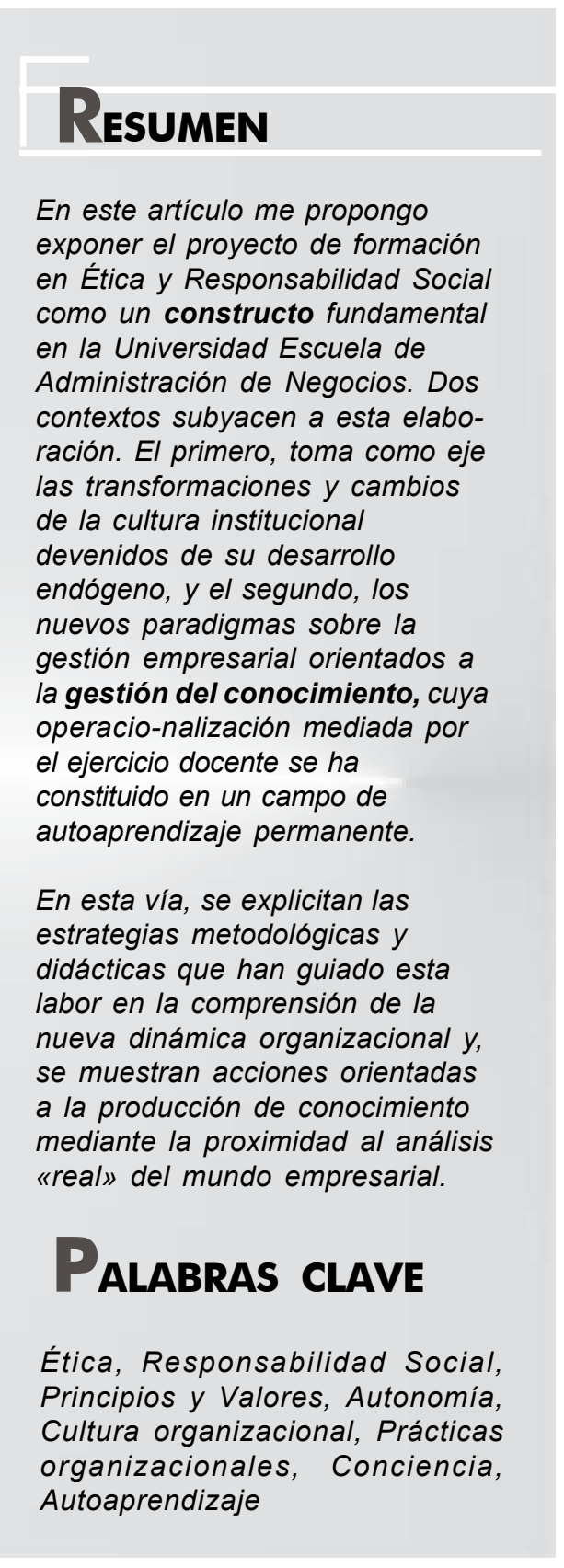

Por:

Martha Cecilia Vidal Arizabaleta *

\section{INTRODUCCIÓN}

\begin{abstract}
V
isibilidad y Reconocimiento. Dos exigencias "prácticas" frente a lo ético en el mundo actual. La ética: un "modo del ser", un campo teórico e investigativo fundamental de búsqueda: un "constructo". Con diversos tonos y matices culturales, la actuación ética, se ha convertido con el paso del tiempo en una necesidad de la vida misma; de las organizaciones y de todo el tejido social en el mundo actual.
\end{abstract}

\subsection{Aprender y desaprender postulado básico}

La historia de las ideas nos ha legado pensadores cuyos planteamientos bordean el tiempo y sobre cuyas comprensiones hemos edificado nuestros más elevados sentimientos y realizaciones humanas. Un acercamiento conceptual al campo de la ética, profundizando en las ideas expuestas

\footnotetext{
* Filósofa-Investigadora. Asesora y Consultora en empresas del sector privado. Catedrádica de Ética y Responsabilidad Social. Departamento de humanidades, EAN.
} 
nos remite en primer lugar a los clásicos. Pensar desde la filosofía los problemas humanos, extraer ideas, recomponerlas, resignificarlas es tarea fructífera. Es inconmensurable el valor de la mirada histórica sobre las experiencias humanas como constructos individuales y colectivos, en donde se fueron prefigurando nociones gruesas como el ser, el deber, la libertad, la autonomía, el respeto, la amistad, la política, los valores...., en fin, lo humano y la vida misma.

Hechos tan enigmáticos e ininteligibles que en la experiencia humana y social, nos sitúan siempre ante nuevas circunstancias, nos concitan a abrir nuevos horizontes de comprensión.

La capacidad de reconocer lo propiamente humano ${ }^{1}$, se advierte en cada enfoque teórico. La multiplicidad de inflexiones que se encuentra en cada autor y cada corriente de pensamiento, nos muestra de diversas formas, que si bien la comprensión teórica y conceptual es necesaria y fundamental, no es suficiente para describir la experiencia humana. El theoros, la contemplación, el asombro, la inquietud, el preguntar, siguen siendo nuestras mejores herramientas para incursionar en los fenómenos del mundo en una forma diferente a la meramente conceptual. El tránsito a la transformación, al cambio, a la investigación misma de los fenómenos es una consecuencia inevitable puesto que a través del tiempo los grupos humanos requieren resignificar su mundo, reconstruir y a su vez construir mundo a partir de las experiencias vividas, y posteriormente volver al camino inicial y así sucesivamente.

\section{Abstract}

In this paper I present a educational project on Ethics and Social Responsibility as an analytical construct for Universidad Escuela de Administración de Negocios. Two basic concepts support this proposal. The first considers as a starting point the institutional transformations and cultural changes coming from its endogenous development and the second, the new paradigms of business management focused on knowledge management, whose everyday workings, mediated by teaching, have become and area of constant self-learning. I put forward the methodological and didactical strategies that have guided entrepreneurs' formation, based on a comprehensive organizational dynamics. I also detail actions geared toward knowledge generation through analysis of actual "real" cases of the business world.

\section{KEY WORDS}

Ethics, Social Responsibility, Values, Autonomy, Organizational Culture, Organizational Practices, Conscience

\footnotetext{
1 Son propicias, controversiales y reveladoras las lecturas de filósofos como: Platón, Diálogos como ritón, la República, I.ysis, Aristóteles. Ëtica Nicomaque; San Agustín Confesiones.Kant. Respuesta a la Pregunta ¿Qué es la ilustraciòn? Nictzsche: Humano demasiado humano, el Anticristo, Aurora, Marx: las Tesis sobre Feuerbach y los Escritos y Manifiestos, Heidegger: Ser y Tiempo: Sartre: el existencialismo es un Humanismo; Habermas: Perfiles filosófico políticos, Escritos sobre moralidad y Eticidad, Adela Cortina: El mundo de los Valores, Ëtica de la Empresa, Fernando Savater. La dimensión ética del empersario, entre otros.
} 
El ejercicio de la autonomía y de la libertad en la construcción de mundo exige la superación del individualismo propio de las sociedades contemporáneas, superar la visión de vacío de la que habla Lipovetsky ${ }^{2}$ para emprender una acción colectiva de sujetos autónomos, creativos, comprometidos consigo mismos, con sus congéneres e inmersos en contextos de acción que los determinan en forma particular. Cuando dilucidamos formas de experienciar nociones abstractas estas cobran fuerza vital, y es posible aprehenderlas y agregar valor a los aprendizajes, superando las esferas de dominación e instalación de los mismos en la cultura. El saber de esta forma se construye permanentemente, se afina y, a su vez, mediatiza otras formas de acción importantes para la vida misma.

Desde estos planteamientos, se entiende por qué consideramos que el ámbito de formación en el saber ético es un constructo permanente de acuerdo con las condiciones propias de la circunstancia que se vive. $Y$ de una forma $u$ otra, todos los actores están en un proceso constante de comprensión y transformación de sus creencias y prácticas cotidianas. El lenguaje en este contexto alcanza un papel preponderante, porque es a través de las expresiones lingüísticas que se lleva a cabo la socialización y la incorporación de estos conocimientos a los demás grupos humanos.

\subsection{Ideas greminales: los retos, lo deseable y las vivencias éticas en el mundo empresarial}

Con frecuencia, en el pasado -y aún en el presente-, "ética" y "negocios" aparecen como términos contrapuestos, en razón a una percepción distorsionada de la relación utilidad y beneficio. Se excluye de modo intencional, el sistema de valores, que es connatural a la acción humana. Se elimina, se ubica como implícito, o se desconoce su importancia, dando como resultado flaqueza, insatisfacción y empobrecimiento de la acción humana. No es una visión catastrófica, es más una resultante histórica del influjo de los sistemas económicos, por fortuna susceptible de transformación.

Así, una época como la nuestra, en donde el management ha tomado una fuerza incalculable, y en donde se ha producido el auge y decaimiento de varias organizaciones a todo nivel y ha crecido la complejidad de los sistemas sociales, productivos y de servicios, requiere el aprendizaje de la ética empresarial y otros modos de actuación que respondan a las exigencias de nuestro tiempo. Esta necesidad se percibe no solo en el ámbito interno empresarial, en lo que compete a su dinámica y procesos de producción y negociación, a los miembros de las empresas, sino también a quienes trabajan en las restantes organizaciones con quien éstas se relacionan.

A este respecto, la experiencia nos ha ido mostrando que las empresas que sobreviven y logran mejores resultados son precisamente aquellas que también han involucrado en su quehacer cotidiano, en su forma de "vivir", un conjunto de valores morales; valores que componen un nuevo modo de entender la empresa, una nueva cultura empresarial: una nueva forma de contrarrestar las situaciones contradictorias y ambiguas derivadas de imágenes, de simbolismos, de mitos, sesgos y ficciones de la vida práctica que dan paso a lo perverso, a lo anómalo, a lo patológico.

\footnotetext{
2 Gilles I.ipovestsky. La era del Vacío. Ensayos sobre el individualismo contemporáneo. Anagama, 10a.edición,2001.
} 
Concebida así, esa nueva cultura empresarial, tiene como condición de posibilidad el contexto de una ética cívica, en lo que concierne al pleno ejercicio de los valores como la libertad, la igualdad, la solidaridad, la cooperación, la participación, el diálogo, la confianza y el respeto, concretados en los derechos humanos. También exige, la incorporación del valor de la tolerancia activa, y la negación de proponer a otros el propio ideal de vida, desplegando para ello, la fuerza activa del diálogo, del testimonio, para acrecentar la posibilidad de llegar a acuerdos y acciones que satisfagan las necesidades de cada actor, quien construye y significa como partícipe en estos complejos escenarios de convivencia.

Todo ello significa que cada fuerza vital de la organización vive y se sustenta de acuerdo con esos valores y derechos, y que las instituciones y organizaciones de tales sociedades cobran su sentido al protegerlos y defenderlos. Por eso, todas ellas han de impregnarse de los mencionados valores, respetar y promocionar los derechos morales, e incorporarlos a su quehacer cotidiano, ya que, en caso contrario, quedan moralmente deslegitimadas y se convierten en espacios de frustración y dolor.

La meta de la actividad empresarial es la satisfacción de necesidades humanas a través de la puesta en marcha de un capital humano -los recursos humanos a todo nivel-, es decir, las capacidades de cuantos cooperan en la empresa. Por tanto, el bien interno de la actividad empresarial consiste en lograr satisfacer esas necesidades, y de forma inseparable, en desarrollar al máximo las capacidades de sus colaboradores, metas ambas que no podrá alcanzar si no es promocionando valores relacionados con la responsabilidad social, una moral de la excelencia, códigos de conducta empresarial y una ética de los negocios. Lo anterior, tanto en lo que concierne a las relaciones externas de las empresas ${ }^{3}$ o de los profesionales independientes con sus clientes, proveedores, con los poderes públicos, entre otros, como en las relaciones internas entre personas en la empresa, incluyendo a los dirigentes.

Sobre lo expuesto cabe postular, sin lugar a dudas, que la educación y el desarrollo moral habrán de pasar a formar parte de un desarrollo organizativo y, que la reflexión, comprensión y vigilancia colectiva de las acciones de las organizaciones conformadas como "comunidades morales"4 permitirá reducir el abuso, la inercia de las instituciones, la anarquía, los conflictos, la corrupción y las "desviaciones perversas" en general que hacen parte del mundo empresarial moderno.

Hemos heredado enfoques y visiones al respecto del mundo ético, así como, conocimientos y construcciones teórico-prácticas fundamentales, sobre cuya base alcanzamos paulatinamente una comprensión más profunda de los hechos humanos. El saber ético nos remite así, de forma inmediata, a un marco de relaciones humanas dada su deriva comportamental como "saber práctico" 5 .

De esta comprensión, de la investigación y de la práctica misma que nos da la interacción humana es que se entiende -en lo que siguela formulación de un ideario en principios y valores como base para el desarrollo del proyecto educativo a nivel institucional y la explicitación concreta de los marcos metodológicos de acción en estos aprendizajes, que trasciendan las aulas y adquieran capacidad de transformación a nivel de los colectivos en los que intervenimos regularmente.

\footnotetext{
3 Al respecto, consultar: James E. Post, Lee E. Preston, Sybille Sauter Sachs. Redefining the Corporation: Stakegholder Management and Organizational Wealth (Stanford Business Books).

4 Jorge Etkin. La doble moral de las organizaciones. Los sistemas perversos y la corrupción institucionalizada McGraw Hill, $1^{\text {a }}$ edición, 1993.

5 Adela Cortina. El mundo de los Valores. “Ética mínima” y Educación, 1ª edición, 1997.
} 


\title{
2. LA VIDA INSTITUCIONAL: PRINCIPIOS Y VALORES
}

\author{
Para la EAN, un sistema educativo debe facilitar el aprendizaje del estudiante \\ en lo que quiere y necesita; permitirle conocer cómo aprender más fácilmente \\ y motivarle a desear aprender, especialmente en las cuestiones que necesite \\ para satisfacer sus propios deseos; finalmente, ser socialmente útil. \\ La educación debe proporcionar al estudiante la facilidad de seleccionar \\ y perseguir objetivos. Por ello, la educación en la edad de los \\ sistemas debe enfocarse al proceso de aprendizaje, \\ no al de enseñanza.
}

La existencia humana se desenvuelve en entornos complejos y cambiantes de acción. El trabajo y la interacción que se lleva a cabo con las personas en los ámbitos educativos son de naturaleza cambiante y caótica, tanto así, que se producen desequilibrios en las mismas. Las crisis que se presentan exigen una gran capacidad de los actores responsables para acompañar los procesos de transformación de las condiciones iniciales. El maestro, como en el caso de los líderes ${ }^{6}$, debe hacer un trabajo consigo mismo, de autoconocimiento consciente que le brinde la oportunidad de "ponerse en los zapatos del otro". Una especie de desarrollo espiritual que le permita comprender desde sí mismo el malestar y el gozo al enfrentar algunas de las situaciones que requiebran la existencia humana. Sólo así estará en capacidad de respetar los ritmos propios de cada cual, y afinará su capacidad de percibir la singularidad de las situaciones, liberándose de estereotipos o prejuicios

Los planteamientos que vienen a continuación se basan en la presunción de que la realidad puede ser vista como una integración de elementos percibidos por las personas a través del intelecto, vividos a través de la emoción y el sentimiento, la intuición, la capacidad de respuesta ante situaciones cambiantes, y demás elementos de la relación con el mundo. En esta vía, son más una experiencia interior, una búsqueda de sentido, la resignificación permanente de la acción, más que una ruta demarcada e impuesta.

\subsection{Declaración de principios y valores $^{7}$}

\section{La actividad docente: Búsquedas, realizaciones y autoconocimiento}

Desde el ideario de los fundadores la perspectiva de la actividad docente está orientada a: Contribuir a la cristalización del proyecto de vida trazado por cada estudiante, tanto en cuanto hace a su progreso intelectual, a la eficiencia de su futuro desempeño profesional y al enriquecimiento cultural. En consecuencia, en la institución se cree que la comunión de esfuerzos debe coadyuvar a la realización personal de cada estudiante, a la consolidación del prestigio corporativo y al cumplimiento de los preceptos contenidos en la misión y la visión.

6 William Glasser. Teoría de la Elección. Ver el interesante planteamiento del Dr. Glasser sobre Dirección por Liderazgo, en el capítulo 11. Paidós, $1^{\text {a }}$ edición, 1998.

${ }^{7}$ Declaración de Principios y Valores. Documento para Docentes. (Este documento fue preparado a partir de las directrices de la Doctora Cecilia Crissien de Perico. La coordinación editorial del Centro de Investigaciones y la redacción del Doctor Alberto Ortiz Gómez. Fecha de Publicación: Diciembre 17 de 1990) 
En este sentido, en nuestro escenario académico se valora la voluntad y disposición de los estudiantes para asimilar nuevos conoci-mientos. Se fortalece su actitud emprendedora, y se acrecientan comprensiones sobre la necesidad del digno comportamiento moral y social, así como el ejercicio del liderazgo en las fronteras laboral o empresarial, actuando como profesionales reconocidos no solo por sus destrezas, habilidades y actitudes, sino por la naturaleza de su inteligencia moral, emocional y social. Creemos, que este propósito vinculado a la formación integral de nuestros educandos, es afín al sano principio de hacer patria, de acatar los principios que rigen la educación superior, de velar por el estricto cumplimiento de la constitución y las leyes colombianas, para construir los cimientos de una mejor nación en beneficio de las futuras generaciones, y coadyuvar así, a la consolidación de las metas de equidad y justicia propias del sistema democrático.

En un ambiente plural y multicultural, la praxis que provee la educación universitaria, sumada a los ambientes de intervención social en los cuales el estudiantado participa, son propicios para generar las transformaciones mentales y actitudinales exigidas para el conocimiento y reconocimiento de otras realidades que conforman la vida de la nación en los terrenos económico, social, político, cultural y tecnológico. Concientes de ello, la mayoría de acciones académicas de la EAN están fuertemente encaminadas a la formación de profesionales responsables, honestos, eficientes, disciplinados, probos y creativos, en función de un espíritu de servicio a la sociedad.
Es por eso, que la labor académica se orienta al desarrollo de líderes que contribuyan activamente a la solución de las necesidades sociales, teniendo en cuenta la plena vigencia de los derechos del hombre. En consecuencia, al preguntarnos: ¿Qué tipo de personas pretendemos situar en los ambientes sociales o empresariales?, no dudamos en afirmar que personas con valores, fieles a sus principios, con conciencia social en sus actuaciones, promotores permanentes de estos mismos valores y fieles al principio según el cual la grandeza del hombre se mide por el tamaño de sus pensamientos".

Por otra parte, La integración de planes de estudio que interpreten las necesidades planteadas por el entorno empresarial, de estrategias pedagógicas dispuestas para ubicar al estudiante como responsable directo del proceso de aprendizaje y de una labor investigativa coherente con la misión y la visión, auspicia la formación integral de personas reconocidas por la destreza en el descubrimiento, la valoración y el desarrollo de talentos humanos, que comulguen con el proverbio: "Se nos paga para actuar con entusiasmo, crear y sugerir, y no para sumergirnos en el letargo de la mediocridad".

En este contexto, los docentes como gestores y artífices de los objetivos institucionales asumen responsablemente la guía de sus acciones desarrollando autoconocimiento y aplicación práctica de las siguientes ideas rectoras en su quehacer. 


\subsection{Docentes: vida y vivencias. Ideas rectoras}

\begin{tabular}{|c|c|}
\hline RESPONSABILIDAD & $\begin{array}{l}\text { Como soporte de las actuaciones en el quehacer académico, exige } \\
\text { dar todo de sí; no reservar conocimientos en el momento de enfrentar } \\
\text { un auditorio; convertirse en devoradores de nuevas ideas y aceptar } \\
\text { que mientras los sabios buscan la sabiduría, los necios piensan que } \\
\text { ya la encontraron...Ser responsable en el escenario docente implica } \\
\text { irradiar optimismo ante nuestros estudiantes, convencerlos de su } \\
\text { potencial, estimular en ellos la idea de soñar y forjar grandes } \\
\text { ideales....ser responsable... implica tener una conciencia centrada } \\
\text { en la vida; abandonar la costumbre de juzgar y cultivar un } \\
\text { comportamiento motivado por el amor y no por el temor o la } \\
\text { ambición. }\end{array}$ \\
\hline COMPROMISO & $\begin{array}{l}\text { La práctica docente es exitosa si se comprende que los grandes } \\
\text { logros no se sustentan en la fuerza sino en la perseverancia... el } \\
\text { compromiso es consigo mismo, con la comunidad estudiantil y con } \\
\text { el país }\end{array}$ \\
\hline $\begin{array}{l}\text { AMISTAD, RESPETO } \\
\text { Y JUSTICIA }\end{array}$ & $\begin{array}{l}\text { El apropiado manejo de las relaciones humanas ha constituido un } \\
\text { bastión fundamental del éxito alcanzado por los grandes líderes } \\
\text { mundiales y se centra en respetar a los demás sin condiciones } \\
\text { asociadas con la posición económica, el nivel intelectual o el sitio } \\
\text { ocupado en la sociedad. La sana convivencia social también precisa } \\
\text { valorar y respetar la opinión de los demás, no aprovechar el poder } \\
\text { para apagar voces y pensamientos contrarios....La relación con los } \\
\text { estudiantes debe impregnarse de afecto, sustentarse en el cultivo } \\
\text { incesante de la amistad y abonarse con normas elementales de } \\
\text { cortesía relacionadas con el trato amable. Por ello, la sabiduría y la } \\
\text { posición ocupada en la institución no pueden esgrimirse como } \\
\text { armas para ofender a los demás, porque se corre el peligro de } \\
\text { resquebrajar el orden institucional acordado o de asimilar prácticas } \\
\text { organizacionales desviadas (maltrato, injusticia, humillación,...). } \\
\text { En consecuencia, la autoridad en los escenarios académicos se } \\
\text { fundamenta en la justicia, se ejerce con la virtud y se soporta en la } \\
\text { búsqueda de la excelencia apoyada en la dedicación, la honestidad y } \\
\text { en la profunda satisfacción deparada de servir a los demás. }\end{array}$ \\
\hline AUTOESTIMA & $\begin{array}{l}\text { La autoestima, como variable impulsora del éxito, implica aceptar } \\
\text { que la armonía humana está atada en principio, al aprecio de sí } \\
\text { mismo, y en consecuencia, que la vida se asimila con un libro al que } \\
\text { diariamente se agregan capítulos. El ejercicio docente demanda } \\
\text { valoración constante de la experiencia, el estudio y asimilación de } \\
\text { las diferencias ideológicas y de contexto, y una mente abierta para } \\
\text { asimilar los cambios, los errores y asumir una posición de liderazgo } \\
\text { moral e intelectual ante una comunidad de jóvenes deseosos de } \\
\text { grandes conquistas y de modelos a emular }\end{array}$ \\
\hline TENACIDAD Y VOLUNTAD & $\begin{array}{l}\text { Según lo afirmó Einstein: "Existe una modalidad de energía } \\
\text { más poderosa que todas las fuerzas energéticas conocidas y } \\
\text { consiste en la voluntad humana". Al acoger esta apreciación, su } \\
\text { labor debe reflejarse en abrir el camino que los estudiantes deben } \\
\text { recorrer con el fin de acentuar el espíritu investigativo, la vocación } \\
\text { de aprender, la intención de pensar, el propósito de cambiar, el aporte } \\
\text { permanente e indeclinable de ideas, el sentido crítico, el afán de sobresalir } \\
\text { y el manejo apropiado de los conflictos. }\end{array}$ \\
\hline
\end{tabular}




\begin{tabular}{|c|c|}
\hline PERSEVERANCIA & $\begin{array}{l}\text { Sin importar el campo donde es viable insertar el proyecto de vida, es evidente } \\
\text { que este será alcanzado en directa correlación con la perseverancia, la intensidad } \\
\text { del trabajo, la confianza depositada en el potencial individual, el entusiasmo } \\
\text { puesto a prueba ante las circunstancias difíciles deparadas por la vida, el } \\
\text { trabajo colectivo, la trascendencia concedida al desarrollo del talento humano, } \\
\text { el optimismo que permite transformar las dificultades en oportunidades y el } \\
\text { pensamiento creativo. }\end{array}$ \\
\hline ÉTICA Y MORAL & $\begin{array}{l}\text { Las directrices éticas y el comportamiento moral efectivo son vitales en la } \\
\text { vida institucional. Logran relevancia en el claustro universitario, al fortalecer } \\
\text { el trabajo en equipo y al gestionar y valorar la producción de conocimiento. En } \\
\text { cuanto a las acciones docentes: la honestidad, responsabilidad y transparencia } \\
\text { en el actuar son condiciones que hacen visible la operativización del modelo } \\
\text { educativo como deber-ser, en la valoración de la producción intelectual, en la } \\
\text { objetividad al evaluar conocimientos. Creemos que lo ético y la vida moral } \\
\text { edifican las bases del futuro y son condiciones necesarias para las } \\
\text { transformaciones que la sociedad va requiriendo en su desarrollo. }\end{array}$ \\
\hline $\begin{array}{l}\text { LABORIOSIDAD } \\
\text { Y PUNTUALIDAD }\end{array}$ & $\begin{array}{l}\text {...Una vida inactiva es una muerte prematura, no importa cuanto vivamos } \\
\text { sino cómo lo hagamos y los proyectos de vida fortalecidos en los ambientes } \\
\text { académicos son susceptibles de ejecutar si se pone amor en lo que se hace, se } \\
\text { mantiene vivo el fuego de la esperanza y si se entiende que no son siempre las } \\
\text { difícultades sino el desaliento lo que nos impide conquistar las metas soñadas. }\end{array}$ \\
\hline LIDERAZGO & $\begin{array}{l}\text { El liderazgo en cualquier organización no sólo lo avala la ubicación de cada } \\
\text { persona en la estructura organizacional, toda vez que en la vida real ello no } \\
\text { basta, porque es necesario conquistarlo, servir de ejemplo, trazar metas que } \\
\text { otros no se atreverían a formular; aceptar riesgos, tomar decisiones, buscar } \\
\text { formas de adaptarse a los demás en vez de intentar infructuosamente que } \\
\text { todos se acomoden a las características intrínsecas del líder y luchar por el } \\
\text { beneficio colectivo. }\end{array}$ \\
\hline $\begin{array}{l}\text { BONDAD, } \\
\text { ESPIRITUALIDAD } \\
\text { YALTRUISMO }\end{array}$ & $\begin{array}{l}\text { Entendemos que somos multiplicadores permanentes de su paso por el mundo } \\
\text { de los mortales, y en consecuencia no tiene sentido creer que basta con alcanzar } \\
\text { las metas profesionales previstas, con integrar familias, con dar buen ejemplo } \\
\text { y con una vida plena de comodidades, porque siempre faltará ejecutar acciones } \\
\text { altruistas en beneficio de quienes no tuvieron la fortuna a nosotros deparada. } \\
\text { Una vida espiritual enriquecida alimenta la paz interna exigida para sortear las } \\
\text { dificultades y debe manifestarse en la fe, en las buenas obras, en gestos de } \\
\text { caridad, en el perdón, en el destierro del rencor, en el amor como fuerza que } \\
\text { convierte cada adversidad en una oportunidad y en realizaciones altruistas que } \\
\text { nos liberen del calabozo del ego y nos permitan compartir con los demás. }\end{array}$ \\
\hline
\end{tabular}

Los valores configuran de esta forma un mundo simbólico en la vida diaria. Como bienes elegibles, son símbolos que encarnan nuestras preferencias, prefiguran lo que es deseable y permiten la comunicación interpersonal y social. No sirven para efectuar una mera descripción de las cosas sino para asignarles relevancia y significado. No apuntan a dimensiones cuantitativas sino cualitativas. Se expresan en el ámbito del sentido, del lenguaje y del diálogo, y su praxis les da visibilidad. A partir de esta intencionalidad, miremos ahora en detalle el campo metodológico de acción para los aprendizajes esperados en el campo axiológico, en lo que compete a la formación en ética y responsabilidad social. 


\section{ENFOQUES DE APRENDIZAJE. LA COMPLEJIDAD DE LAS ORGANIZACIONES}

$\mathbf{E}_{\mathrm{n}}$ desintegración social, causada por el abandono por parte de las personas y de las instituciones de sus valores que podríamos denominar naturales, está afectando todos los entornos organizacionales. Una simple mirada a las publicaciones de los diarios y a los informes de diagnóstico ${ }^{8}$ sobre desarrollo humano de los organismos internacionales, nos dejan reconocer aspectos como la disociación entre los protagonistas sociales, entre las organizaciones mismas y la sociedad y, cómo crecen y se agravan los conflictos internos y externos; la inusitada y utilitaria volatilidad de las relaciones; las prácticas desviadas de los objetivos misionales, y lo que es más preocupante, la falta de controles efectivos ante el crecimiento desenfrenado de negocios de dudosa o nula conveniencia social.

Si bien se han mejorado con el tiempo algunas de las tácticas y estrategias empresariales, éstas no han manifestado igual fortaleza en el análogo crecimiento en la sabiduría y en el sentido ético de los empresarios cuya influencia en el resto de la sociedad debería por otra parte ser mucho más proactiva. Si suponemos -en sana lógica- que la actuación empresarial imbrica tener valores morales y transmitirlos, estos se vuelven difusos por cuanto se sigue privilegiando la relación costo/ beneficio y, en esta relación, la movilización de esfuerzos institucionales para atender las demandas humanas resulta ser insuficiente y de menor envergadura.
No se observa fácilmente una equivalencia entre la productividad y el construir escenarios enriquecidos de vida para quienes son el sostén de las organizaciones. Hablar de emprendimiento, desde nuestra comprensión, significa movilizar todos los esfuerzos en pos del bienestar integral, la búsqueda de la satisfacción, y la consecuente obtención de resultados favorables para todos según las metas trazadas.

Por ello, se hace indispensable desarrollar nuevas sensibilidades en los noveles profesionales, que les provean un acercamiento más certero de cara a estos problemas. Cuando se entiende que Emprender es tarea tesonera y espinosa que requiere elegir, alta dosis de dedicación y esfuerzo, confiar, combatir, renunciar, tomar riesgos, cumplir la palabra, motivar, cooperar, acciones en las que el hombre pone en juego sus valores, sus percepciones, sus creencias, sus concepciones y necesidades vitales y su libertad. De esta comprensión se deduce, que una práctica empresarial exitosa, requiere de suyo, no estar de espaldas a la dimensión ética, ni su responsabilidad puede quedar centrada únicamente en objetivos de negocio medibles.

En este marco problémico y con la finalidad de aprender - desaprender, y/o aprehender la forma como se comportan los sistemas reales, llevamos a cabo un proceso de formación que va desde la indagación teórica y conceptual: dimensión epistemológica la cual provee comprensiones de base, al campo de la

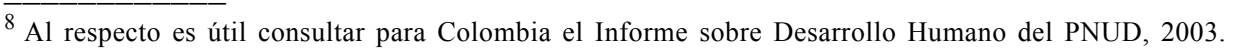


aplicación práctica: por ejemplo, incorporamos actores reales (Directivos, Empresarios) en la ejecución de ejercicios para identificar las habilidades de gestión que se requieren en la toma de decisiones. En otras ocasiones, tomamos casos estructurados en el campo empresarial con diferentes propósitos de análisis. Es indescriptible la vitalidad que adquiere el aprendizaje, la comprensión significativa sobre los planteamientos teóricos de autores incluso antagónicos. Se abre así, la posibilidad para crear soluciones: conocimiento práctico, como valor agregado en el aprendizaje de estudiantes y colectivo en general. En lo que sigue se ampliarán estas experiencias.

\subsection{La práctica vital. El análisis situacional}

\author{
Ni en el mundo, ni fuera del mundo, cabe \\ pensar nada que pueda ser considerado como \\ bueno sinrestricción, excepto una buena \\ voluntad \\ E. Kant
}

Aprender a partir de situaciones concretas es adentrarnos en territorios desconocidos. Encontrar la lógica de los procesos y entender las motivaciones humanas, tiene el encanto del descubrimiento. No podemos aseverar nada hasta tanto no tengamos a bien mayores comprensiones y un conocimiento del cual partir. Por ello, incursionar desde el análisis de casos nos ubica en el campo de la realidad y es allí, en donde ponemos a prueba nuestros conocimientos y nos preparamos para conocer y dilucidar las formas como se presentan las interacciones sociales, los conflictos y dilemas que se plantean como resultado de las mismas en el mundo real.

No bastan los parámetros, ni los principios esbozados para guiar las conductas humanas en cualquier entorno. La coexistencia de responsabilidades y deberes también son parte de procesos ideológicos manejados por actores sociales o participantes de un determinado grupo humano que regularmente actúan bajo estructuras de poder, de dominación. Vemos por ejemplo, cómo se predica solidaridad y se decide con base en beneficios individuales, se habla de igualdad mientras se condena a las minorías étnicas a trabajos inferiores o se callan sus voces, o se habla de libertad en ámbitos democráticos pero se persigue a quienes piensan diferente.

En esta red de relaciones, y teniendo como eje el análisis de las situaciones que se plantean a partir de los estudios de caso, una vía de análisis, es situar la ética en la perspectiva del deber ser, en la función social de las misiones $y$ de los roles de las organizaciones en su conjunto. Desde esta concepción, la ética se basa en el concepto de imperativos categóricos o universales y es de utilidad el concepto de deber ser kantiano para revisar la racionalidad de las acciones, puesto que para Kant ${ }^{9}$, un imperativo es un concepto a priori, que expresa un deber, una ley moral. En materia de la ética se trata de un deber de virtud (no jurídico) que está fuera de toda condición o interés externo, porque vale por sí mismo. Así, el respeto a la libertad o a la idea del bien, no son conceptos obtenidos en forma empírica, son ideas regulativas y sólo cabe defenderlas y rechazar los argumentos de quienes pretenden negarlas.

En este contexto, lo ético se refiere a los fines en sí mismos. Es decir, no son principios o mandatos que se regulen según circunstancias o contingencias. La complejidad de lo ético radica en que los imperativos (el deber ser) no están conectados entre sí de manera lineal. No pueden razonarse diferenciando claramente

${ }^{9}$ Enmanuel Kant. Metafísica de las Costumbres. Amorrortu, 10a.edición, 1988. 
entre medios y fines, entre causas y efectos, lo superior e inferior, positivo y negativo. Inclusive en la axiología, cuando se habla de jerarquía de valores, esto no significa que ellos se encuentren ordenados dependiendo unos de otros.

La otra vía de análisis, nos remite al campo de la explicación de los hechos morales, en donde la ética uthens, es decir, la ética social aplicada nos proporciona no sólo el análisis de los posibles conceptos sino también de los considerados pertinentes. En este sentido Maclntyre $^{10}$ ha señalado que la ética está formada por descripciones de segundo orden respecto de un discurso de primer orden que incluye a las expresiones morales sobre la conducta cotidiana. En su nivel la moral ofrece normas de conducta y conceptos para intentar contestar preguntas de esta naturaleza:

\section{¿Qué debo hacer para actuar correctamente $y$ ser reconocido como integrante de un orden social más amplio, con instituciones, ideas y creencias ya determinadas? ¿Cómo debe evaluarse el trabajador que roba por hambre o estado de necesidad? ¿Cómo pensar en el gobierno que trasgrede los derechos humanos por las llamadas razones de Estado?}

Es el tema de la contextualización de los comportamientos sociales en grupos y organizaciones, con el objeto de evaluar la legitimidad de los valores aplicados.

Intrínsecamente a lo ético (en el contexto y en las organizaciones) corresponde reflexionar si lo moral es siempre y sólo intuitivo y emocional. Pensar si se trata de cumplir con un precepto o mandato social que además tiene fundamentos lógicos, si los juicios morales deben ser fundados y razonados, y por lo tanto, si pueden ser discutidos y puestos a prueba.
En estas situaciones éticas, la pregunta que surge es si son posibles las normas de conducta válidas objetivamente, más allá de las apreciaciones personales. Por ejemplo, en ciertas organizaciones sociales: ¿Qué significa la lealtad al fundador, la responsabilidad social, la equidad en los actos? y también ¿Qué significa la lucha competitiva o la solidaridad como valor en ese sistema?

En el plano de la ética social se discuten entonces los criterios externos, aquellos que los integrantes toman como referencia para darle validez moral a sus acciones o para definir su sentido de la responsabilidad. En este nivel los problemas se razonan desde la sociedad hacia las organizaciones que la integran. Dado que no es factible ordenar lo moral en una jerarquía inmutable de valores, el problema de la ética es el alcance, la prioridad y la coherencia entre principios que afectan otros principios. De ahí la bondad del análisis situacional que proveen los estudios de caso para la comprensión de la trama de relaciones en determinado marco ético de acción.

\subsection{El sentido de la responsabilidad social}

Existe un buen número de publicaciones sobre responsabilidad social de la Empresa, sin embargo, puedo atreverme a afirmar que el tema se ha centrado extensamente en asuntos de tipo ambiental, desarrollo sostenible y producción más limpia, que sin lugar a duda es uno de los frentes de gran atención por la importancia que ello reviste para el planeta y el futuro de la humanidad, pero no debe ser el único.

\footnotetext{
10 MacIntyre, Tras la Virtud. Editorial Crítica. Barcelona, 1998.
} 
A este respecto, creemos que para efectos de lograr una sensibilización más amplia a nivel de la formación profesional, se hace necesario e imprescindible conocer, pensar e indagar problemas que van desde lo humano (aspectos relacionados con el buen trato, la convivencia, el bienestar emocional) hasta lo laboral, social, ambiental y cultural, sobre cuya base se pueden conjugar acciones más integrales en todos los ámbitos de la actividad empresarial.

En este sentido se busca entender, explorar y poner en práctica nuevas formas de conjugar los intereses empresariales a los intereses humanos, en donde el mayor beneficio sea la idea directriz en ambos sentidos. Lograr un justo medio, un punto de equilibrio entre estas fuerzas que están en permanente tensión.

Teoría y praxis siguen siendo la dupla dialéctica por excelencia para acercarse al análisis de la realidad. El conocimiento de la dinámica empresarial que aportan las universidades y los grandes centros de investigación en negocios que se ocupan de temas como calidad, gestión, responsabilidad social y direccionamiento, entre otros, hallan profundización mediante la realización de ejercicios y simulacros que tienen como eje la dinámica empresarial. Problemas, conflictos, necesidades, decisiones de mejoramiento e inversiones, riesgos, oportunidades de negocios, alianzas estratégicas entre otros, son abordados utilizando por ejemplo, la metodología de los stakeholders, y los resultados obtenidos de estos análisis, son el valor agregado para construir conocimiento válido.

En esta vía, destacamos los estudios que se vienen realizando en el medio empresarial colombiano mediante la utilización de la teoría de los stakeholders, una valiosa herramienta metodológica de análisis teórico y situacional. Puntualicemos al respecto, algunos elementos de su concepción teórica. La teoría de los Stakeholders (Margery Blain, Stakeholder vs Shareholder ${ }^{11}$ ) es un enfoque teórico-metodológico el cual se basa en el principio ético articulado por Immanuel Kant: "Todos los seres humanos se deben tratar como personas"... se constituye en un excelente eje teórico para revisar el tejido social en cuanto a responsabilidad social.

Este enfoque define a los "interesados" como, los surtidores, los clientes, los empleados, los accionistas, y la comunidad local. Cada uno de estos grupos del Stakeholder tiene derecho a no ser tratado como el medio para obtener un fin (Donaldson). Los "stakeholders" pueden ser identificados como clientes, empleados, proveedores y los accionistas. Los empleados tienen sus trabajos en juego. Los surtidores tienen su propio negocio en juego. Los accionistas son, por supuesto los propietarios de las prácticas, sino de las mismas entidades.

El primer principio de esta teoría es que, la corporación se debe manejar para el beneficio de sus"interesados. Que los derechos de estos grupos deben ser asegurados, y, además, los grupos deben participar, en las decisiones que afectan substancialmente su bienestar (Donaldson)

El segundo principio de esta teoría es, la gerencia un lazo fiduciario a los interesados y la corporación como entidad abstracta. Debe actuar en el interés de los interesados como su agente y estos deben actuar en los intereses de la corporación de asegurar la supervivencia de la firma, salvaguardando la estancia a largo plazo de cada grupo

\footnotetext{
11 Citado por: Pilar Mayorga y Volmar Jaime González. Fundación Corona La Responsabilidad social de la empresa (Elementos teóricos y experiencias) en: http://www.fundacioncorona.org.co/descargas/PDF_publicaciones/ Responsabilidad/RSEMayorga.pdf (Fecha de consulta: Enero 12 de 2007).
} 
(Donaldson). El segundo principio conduce a creer que si una entidad (la corporación) no sigue el primer principio, el negocio no podrá permanecer en vigente. En conclusión, se viola claramente la teoría del stakeholder de las prácticas de negocio.

La relación de stakeholder-compañía presume ser igual para todos los tipos de interesados. Sin embargo se observa que algunos de los interesados tienen una demanda más legítima en una compañía que otros, esto se da porque la ruta por la cual pueden influenciar las compañías es estructural y de más alcance.

La teoría es desarrollada aquí explorando conexiones entre los interesados y las compañías usando un acercamiento general a la diferenciación social, desarrollada por Archer (1995). El modelo de Archer se basa en una filosofía del realismo. El modelo trata la naturaleza de las relaciones, si compatibleincompatible y necesario-contingente, junto con una observación de las ayudas institucionales que existen. Al examinar la naturaleza de las relaciones y de los contratos entre los interesados y las compañías una penetración más clara se puede ganar en teoría los "stakeholders". El rango de las relaciones de stakeholder-company puede ocurrir porque diversos interesados influyen en las compañías de diversas maneras, y porque algunos "interesados" tienen más influencia en las compañías que otra. Se cree que tal análisis puede también realzar la interpretación de la teoría de la legitimidad.

En lo que respecta al tema de la responsabilidad social, mediante la metodología de los stakeholders el análisis de casos es interesante percibir que hay una resistencia velada en las organizaciones para dejar ver esta cuestión. Como bien lo expresa Enrique Sendagorta ${ }^{12}$ : Hoy nadie deja de ver las consecuencias de la naturaleza social de la empresa. Se ponderan por un lado sus aportaciones y por otro sus externalidades, su capacidad de consumir riqueza común y bienestar. También se reconoce que la dinámica tecnológica, la competencia, la complejidad de los intercambios sociales, y la dificultad en ordenar las expectativas de las personas en una sola escala de valores aceptable para la mayoría, someten a la empresa a solicitaciones contradictorias que muchas veces dan lugar a conflictos abiertos tanto internos como externos.

Junto a los accionistas, interesados en el resultado de la empresa y los empleados, interesados en su empleo y en sus retribuciones, han aparecido nuevos protagonistas sociales formando un amplio grupo de interesados en la empresa y de alguna manera afectada por su actividad. Simplificando podríamos decir que la responsabilidad comúnmente percibida por el empresario era antes frente a los propietarios, a los accionistas, a los "stock holders", y hoy hay que pensar en un círculo de interesados, "stakeholders" mucho más amplio. Una simple enumeración de interesados nos hace ver la complejidad de relaciones de las que pueden derivarse responsabilidades:

- Empleados y trabajadores de la empresa.

- Sindicatos. Asociaciones de cuadros.

- Autoridades y entes a quienes concierne el problema del empleo y de la Seguridad Social.

\footnotetext{
12 http://www.unav.es/empresayhumanismo/4publi/cuadernos/pdfs/03o.pdf. Ver artículo de Enrique de Sendagorta. La responsabilidad social del empresario. Cuadernos empresa y humanismo. No.3 (Fecha de consulta: enero 15 de 2007).
} 
- Accionistas. Mercado de capitales. Bolsa.

- Financiadores, proveedores y aseguradores de la empresa.

- Asociaciones de consumidores.

- Comunidades locales y regionales.

- Representantes de minorías raciales, culturales, etc.

- Partidos y cuerpos políticos.

- El Estado con todo su aparato legal y administrativo.

A esta relación habría que añadir otra con alguna enumeración de instituciones y cuerpos que también importan:

- Los centros de educación y las Universidades.

- Los medios científicos, artísticos e intelectuales.

- El periodismo y los medios de comunicación (como tales).

- Los estamentos religiosos.

- Las actividades benéficas.

A la complejidad del trato ponderado, -agrega Sendagorta-, con tantos interesados se suma en muchas ocasiones la desconfianza pública ambiental alimentada por los accidentes ecológicos, los fraudes, las especulaciones escandalosas, los nuevos estilos de la persecución del dinero sin ninguna creación intermedia de verdadera riqueza y tantos otros vicios graves que no pueden sino suscitar la pérdida de credibilidad y de legitimación de los empresarios.

Se advierte así, que la responsabilidad social de la empresa combina aspectos legales, éticos, morales y ambientales, y es una decisión voluntaria, no impuesta, aunque exista cierta normatividad frente al tema. Si bien, la búsqueda entendible de productividad y competitividad son la razón que lleva a que las decisiones gerenciales hagan una valoración del costo beneficio.

También existe la necesidad de inversión en lo específicamente humano como una forma de contrarrestar el impacto de la misma dinámica del mercado, con sus tendencias neoliberales y la gran necesidad de mantenerse o sobrevivir en un sistema de relaciones complejas y desiguales, en donde la ética y la moral, el concepto de justicia y otros aspectos relevantes a principios y valores se relegan y se juega con reglas irregulares haciendo que la máxima Maquiavélica "el fin justifica los medios" impregne toda práctica empresarial y le otorgue una oscura validez.

Contra esta forma de pensar y de orientar acciones conviene determinar caminos nuevos para transformar y comprender a cabalidad que se requieren cambios sustanciales en el lenguaje empresarial en donde aún subyacen pretextos irresponsables, tales como, "si no lo hago no puedo generar empleo", "es la única forma de ser rentable y eso aporta beneficios tributarios que sirven a todos", "el objetivo es sobrevivir a como de lugar"...

La actuación sin escrúpulos y transparencia en las acciones, así como el desconocimiento u omisión de gran parte de los actores de lo que significa ser responsable socialmente ha tenido consecuencias nefastas a lo largo de la historia e impactos variados en el entorno social, humano y ambiental.

El carecer de visión ética, de principios cívicos, sociales y hasta espirituales, convierte nuestra vida en territorios de mayor dolor y sufrimiento, por tanto, la educación en este nivel y la toma de posición efectiva frente a los malestares de la cultura, hace necesario actuar y participar en varios frentes. Por ejemplo, en el cambio de políticas blandas, imprecisas e irresponsables de los gobiernos; gobernantes laxos, permisibles y transigentes; las prácticas desviadas y los sistemas de corrupción; la imposibilidad de pasar del discurso a la acción en el campo ético por parte de entidades educativas y 
organizaciones en general; la ignorancia misma o falta de conocimiento sobre el tema ético por parte de empresarios y actores del sector productivo y comercial o la reducción del mismo a recetas traducidas en decálogos inservibles, impracticables y sin sentido; el bajo escrúpulo de muchos empresarios y personas que conociendo el tema y sus consecuencias, actúan de forma irresponsable; la pasividad e inercia que llena los claustros universitarios en cuanto al impacto social de las acciones devenidas de sus entornos, entre otros.

Frente a este estado de cosas, nuestros esfuerzos están orientados a construir mundo a resignificar la interacción humana desde la práctica vivencial de estos conocimientos; a crear mayor comprensión y conciencia sobre nuestras acciones; a fortalecer el autoaprendizaje de las organizaciones, con miras a la generación de mayor capital social, intelectual y moral en la sociedad.

\subsection{Esfuerzos comunes. Un diálo- go constructivo: La cátedra «transferencia» ${ }^{13}$}

El desarrollo moral es un proceso de crecimiento que ocupa la vida humana. Tenemos como seres humanos la oportunidad permanente de transformar nuestras creencias, hábitos $y$ costumbres. En este sentido, el encuentro en la palabra, en el diálogo abierto sobre la realidad ética empresarial que se realiza en la EAN a través del convenio con la cátedra transparencia, ha sido una experiencia inigualable para conjugar esfuerzos ínteruniversitarios de comprensión sobre el actuar humano en las organizaciones. Se incentiva el diálogo como una forma de trabajo en grupo para comprender y transformar el mundo.
Las personas desarrollan la habilidad de pensar en las situaciones límite en sus vidas $y$ en las organizaciones e idean formas de trascender esas situaciones; el proceso es colectivo. El punto importante de esta experiencia está en trascender la esfera individual hacia lo colectivo, como fuerza transformadora, sin desconocer la importancia de la individualidad en estos procesos y aunando esfuerzos para realizar el objetivo de la cátedra transparencia por Colombia que consiste en:

"contribuir con la formación ética de estudiantes universitarios, futuros líderes de organizaciones públicas y privadas, para que cada uno de ellos, en su ejercicio profesional y ciudadano, encuentre formas concretas de acción para construir "lo público" y luchar contra la corrupción".

Desde hace tres años, hemos participado activamente en el desarrollo del Proyecto de la U a la Ey sus cuatro componentes:

\section{Plenarias ínteruniversitarias}

"Estas plenarias están abiertas al público general y han atraído un gran número de conferenciantes de alto perfil. Se dedican al análisis de grandes debates en el tema de la ética convocando a líderes de organizaciones públicas y privadas, académicos y estudiantes universitarios en torno a una reflexión sobre los valores y los retos éticos que viven las organizaciones contemporáneas, con énfasis en la construcción de "lo público".

Se busca que los temas de las plenarias motiven a los estudiantes a entender la necesidad de desarrollar el juicio moral y a poner como prioridad en esas decisiones una noción clara de lo público"

\section{Seminarios de análisis de casos}

"La cátedra documenta estudios de caso y promueve que los profesores realicen con ese material Seminarios

\footnotetext{
13 La información y los valiosos resultados de la gestión y proyectos de transparencia pro Colombia se puede consultar en:www.transparenciacolombia.org.co.
} 
de Caso dentro de sus cur-sos regulares. Al igual que las plenarias, tienen como común denominador experiencias que han enfrentado el dilema integridad-corrupción.

El análisis de casos permite aproximar a los estudiantes de manera práctica a problemáticas éticas que viven los profesionales y los líderes de las organizaciones contemporáneas, así como también a situaciones en las que decisiones íntegras han sido posibles y se ha garantizado el interés general sobre el particular. Cada caso está acompañado de una nota de enseñanza para orientar al profesor en el trabajo del aula, así como de la reseña bibliográfica de autores nacionales e internacionales que apoya el análisis del caso"

\section{Talleres de Valores en Acción ${ }^{14}$}

"Estos talleres, moderados por Transparencia por Colombia, desarrollan una metodología de juego de roles, para generar una reflexión en torno a los valores desde intereses distintos. Los talleres buscan poner en juego los valores con los cuales los estudiantes enfrentan la toma de decisiones en su vida profesional y personal. También pretenden poner en evidencia la complejidad en el manejo de las relaciones y la gran variedad de grupos de interés que deben ser tenidos en cuenta al enfrentar los retos éticos cotidianos en las organizaciones y en su vida personal".

\section{Intercambio de las experiencias de los profesores en la enseñaza de ética}

"La cátedra propicia espacios de reflexión e intercambio entre los profesores de las diferentes universidades adscritas con el fin de fortalecer el trabajo en equipo en torno a esta iniciativa, intercambiar experiencias pedagógicas sobre la enseñanza de ética y evaluar permanentemente los distintos componentes de la cátedra".

A nivel académico, personal y profesional la cátedra transparencia ha fortalecido en la EAN la valoración de la esfera moral desde la praxis vivencial de estos conocimientos; la integración de varios programas académicos a este ámbito de formación; satisfacción al saber que estamos de lado de la solución de los problemas no de su agravamiento y que somos voces de cambio al promover formas de interacción y conciencia colectiva; y conciencia, compromiso, participación, cooperación y responsabilidad general ante la meta de construcción de un mundo mejor para los habitantes del futuro.

\subsection{La transformación a través de la práctica. Investigación, cono- cimiento e intervención social}

\author{
"La imaginación es más \\ importante que el conocimiento"
}

A. Einstein

Idear y crear soluciones frente a los obstáculos que se presentan en el desarrollo empresarial y poder participar e intervenir en ellos de manera efectiva es otra de las experiencias que cualifican nuestra actividad como formadores en la EAN.

Por ello, destaco la importancia de incorporar competencias investigativas ${ }^{15}$ como estrategia pedagógica en la formación superior en ética y responsabilidad social. A la par de su incorporación, se ha alcanzado mayor visión sobre la formación y aplicación de los enfoques teóricos y axiológicos que subyacen a las prácticas organizacionales. Se ha dimensionado el impacto y oportunidad de los nuevos paradigmas teóricos en el ámbito empresarial colombiano y el valor de su aplicación.

\footnotetext{
${ }^{14}$ En el 2006 los profesores Jorge Munevar y Martha Vidal Arizabaleta, docentes del Departamento de Humanidades de la Universidad EAN, son seleccionados como Talleristas de la Cátedra para realizar los talleres en las universidades del convenio.

${ }^{15} \mathrm{He}$ guiado parte del trabajo de indagación sobre la realidad empresarial, teniendo como eje los planteamientos de la Investigación-Acción Participativa del Profesor Orlando Fals Borda, con ajustes metodológicos a partir de técnicas de investigación documental y diseños pre-experimentales en investigación social. En particular la comprensión del enfoque de intervención sobre la práctica de lo que el denomina los "saberes locales" el cual me ha permitido ahondar en las prácticas y motivaciones que mueven a lideres y gestores de empresas a llevar a cabo sus proyectos. Este enfoque permite a su vez vislumbrar de manera significativa la dimensión ética en la dirección de las organizaciones y determinar los impactos de las mismas interna y externamente.
} 
Adicionalmente, los estudiantes han participado paulatinamente en PYMES de diversos sectores que les ha permitido fortalecer su conocimiento sobre los grandes temas empresariales. Visualizan los vicios y virtudes, tanto de los actores inmersos en la dinámica empresarial, como de las ideas y estrategias trazadas como políticas de desarrollo, mejoramiento o calidad, entre otras.

De todo ello, se ha alcanzado un acervo importante de experiencias en la esfera del saber práctico-vital, cuyo valor agregado se concreta en los aportes que desde la Universidad se realiza a múltiples empresas (del sector público o privado) en el marco de desarrollo de convenios, acuerdos o proyectos.

De otra parte, la actividad investigativa ${ }^{16}$ en la EAN, se traduce en acciones concretas operativas a través de programas y proyectos de investigación.

El objeto central de investigación definido para la Universidad -organización y empresario- se enfoca desde la perspectiva del espíritu emprendedor y de los elementos necesarios para la adecuada promoción de este espíritu.

Igualmente investiga los elementos del entorno y las herramientas necesarias para un adecuado desarrollo de nuevas empresas y nuevos empresarios.

A partir de este marco general, emprendemos varias acciones desde la formación integral en ética y responsabilidad social a saber:

\section{Desarrollo de una línea específica de investigación del departamento de Humanidades: "Cultura universitaria: principios y valores"17 :}

Esta línea se circunscribe a la tercera Línea general de Investigación: sociedad del conocimiento y globalización, dada la relevancia de los estudios que se realizan en este campo y teniendo en cuenta los grandes cambios que está experimentando la sociedad y la economía mundial, los cuales modifican de manera muy significativa en Colombia las posibilidades de creación de empresas y de la promoción del espíritu emprendedor así como los perfiles que exigirá la sociedad para la formación y actuación de los empresarios del nuevo mundo globalizado.

De hecho, el trasfondo de los estudios en cultura universitaria y el abordaje teóricopráctico sobre principios y valores en la cultura institucional, está determinado por la convicción de que sin claros principios de actuación ética y ciudadana el papel de los noveles profesionales sólo será para llenar puestos de trabajo, pero no para transformar y contribuir al progreso social. Ahora bien, sobre la humanidad, se ciernen amenazas muy reales.

Esto nos lleva a preguntarnos por el tipo de formación que se está brindando en el sistema educativo, en la universidad en particular, y cómo se podría orientar dicha formación para que aporte a la resolución de la actual coyuntura social.

\footnotetext{
${ }^{16}$ Trascrito y adaptado de: EAN. Producción intelectual y catálogo de investigaciones 1998-2004, págs.18-28. Tomado de: La Investigación: un tema en serio de la Escuela de Administración de Negocios. Compilador: Rafael Pérez Uribe. MGO Universidad de Québec. Director (e) Centro de Investigaciones EAN.

${ }^{17}$ Documento de trabajo preparado por Martha Vidal Arizabaleta. Catedrática. Departamento de Humanidades, 2003.
} 
Al respecto, uno de los propósitos esenciales de la educación en la EAN es fortalecer y/o reorientar la formación de los estudiantes en principios y valores que les permitan enfrentar las complejas situaciones, asimilar los cambios y buscar soluciones acertadas a los problemas complejos del mundo moderno. Desde esta perspectiva, la formación moral no puede ser impuesta al hombre desde el exterior, requiere de cierto sistema individual de valores, puntos de vista, ideales, los cuales se exigen en el sujeto de forma determinada y que en la misma medida que revelen sus relaciones con los que le rodean, reflejen además un sistema individual de significados, modelos a seguir, los que consecuentemente deben ser la guía de la actuación.

La calidad en la formación del profesional en valores constituye un problema pedagógico complejo, depende no sólo de los conocimientos y habilidades que desarrolle en el currículum universitario sino también de los intereses y valores que regulan su actuación profesional.

El amor a la profesión, la responsabilidad, la honestidad constituyen valores esenciales reguladores de la actuación de un profesional competente.

\section{Desarrollo de habilidades de pensamiento}

Como el proyecto educativo está orientado al desarrollo de competencias, y a la búsqueda de la excelencia y calidad de la educación superior, a la cátedra de ética y responsabilidad social hemos incorporado estrategias de aprendizaje significativo, aprendizaje autónomo, enseñanza para la comprensión ${ }^{18}$, la utilización de mapas mentales ${ }^{19}$ en los procesos de apropiación del conocimiento socio-humanístico, y en la actualidad en lo que respecta a mi propia labor docente he incorporado mis conocimientos fruto de la capacitación y certificación recibida en teoría de la elección, en particular la comprensión sobre las necesidades básicas y el planteamiento del instituto William Glasse ${ }^{20}$ sobre terapia de la realidad y dirección por liderazgo.

Estas prácticas se aplican en diferentes momentos del aprendizaje y se han constituido en herramientas fundamentales para la construcción, apropiación y aplicación de conocimiento en el campo social.

\section{Estudios sobre cultura organizacional. Prácticas organizacionales}

En las distintas experiencias que hemos tenido, se observa que esta es de las intervenciones más enriquecedoras desde el punto de vista del reconocimiento de la forma como se llevan a cabo la dirección, las políticas y las estrategias de las organizaciones de PYMES y MIPYMES de sectores público o privado; se establecen vínculos interinstitucionales y se ponen a disposición de las organizaciones los resultados de los análisis realizados.

Es relevante en este proceso, los beneficios compartidos, la cooperación y el reconocimiento que se operan en ambos lados de la relación: universidad-empresa. Se fortalece por ejemplo, la confianza mutua, por tanto, para ninguna parte pasan desapercibidos los hallazgos $u$ obstáculos, favoreciendo un clima de conocimiento organizacional en donde las personas que intervienen comienzan a descubrir sus propias posibilidades de creatividad, iniciativa y sentido de pertenencia.

\footnotetext{
18 Consultar: Proyecto Zero. Universidad de Harvard.www.pz.harvard.edu/

${ }^{19}$ Buzan, Tony / Buzan, Barry; El libro de los mapas mentales. Cómo utilizar al máximo las capacidades de la mente; Ed. Urano, Barcelona, 1996.

20 Ver: www.wglasser.com
} 
En algunas ocasiones, son las propias organizaciones las que deciden continuar los procesos de mejoramiento y para ello se establecen convenios de asistencia en consultoría y asesoría acordes con las necesidades de cada institución.

El tema de mayor alcance ha estado relacionado con el estudio sobre el "doble discurso de la mentira y la hipocresía" 21 y la forma como estos comportamientos afectan en forma dramática la vida de las organizaciones y a los actores de las mismas. Contamos con información proveniente de más de 300 instituciones de todos los sectores que han participado en estos procesos y estamos en la actualidad en la construcción de casos y documentos de trabajo interno.
Para concluir cabe anotar, que nuestros propósitos están encaminados a hacer de esta práctica académica-investigativa un recurso de autoaprendizaje permanente en la institución, y que a través de su desarrollo, podamos contribuir a enriquecer la vida de las personas, de la universidad y de las organizaciones.

En esta vía también seguiremos orientando acciones hacia la sostenibilidad de la práctica de la ética empresarial y la creación de futuros deseados en medio de una economía globalizada, que demanda nuevas lógicas, y nuevas comprensiones para la acción.

\section{Bibliografía}

Cortina, Adela. El mundo de los Valores. "Ética mínima" y Educación, $1^{\text {a }}$ edición, 1997.

Blanchart, Claudio: La Gestión del Conocimiento. Cosmoseguros No. 74, Panamá, abril de 2000

BUZAN, TONY / BUZAN, BARRY; El libro de los mapas mentales. Cómo utilizar al máximo las capacidades de la mente; Ed. Urano, Barcelona, 1996.

Davenport, T. Ecología de la Información. Oxford University Press, 1999.

Etkin, Jorge. La doble moral de las organizaciones. Los sistemas perversos y la corrupción institucionalizada McGraw Hill, $1^{\text {a }}$ edición, 1993.

Glasser, William. Teoría de la Elección.. Paidós, $1^{\text {a }}$ edición, 1998.

James E. Post, Lee E. Preston, Sybille Sauter Sachs. Redefining the Corporation: Stakeholder Management and Organizational Wealth (Stanford Business Books).

Kant, Emmanuel. Metafísica de Las Costumbres.Amorrortu, 10ª edición, 1988.

Lipovetsky, Gilles. La era del Vacío. Ensayos sobre el individualismo contemporáneo .Anagrama, $10^{a}$ edición, 2001.

MacIntyre, Tras la Virtud. Editorial Crítica. Barcelona, 1987.

Nonaka I, Takeuchi H, The Knowledge Creating Company, Oxford University Press, 1995.

$\overline{21}$ Está en preparación un informe de investigación sobre este proyecto de aula liderado por Martha Vidal Arizabaleta en la cátedra de Ëtica y Responsabilidad Social. 
